most felt, corresponds with a series of outlying masses of carboniferous limestone, which are separate from the main mass of carboniferous Jimestone of the Mendip anticlinal. Whether these are parts of another anticlinal, or owe their position to faulting, I do not know. Westward of Wells these outliers form little knolls, as at Draycott and Westbury. Further east, in the area between Wells, Shepton Mallet, and West Compton, they form a group of prominent hills, whose valleys are occupied by later formations. If such outliers exist east of Shepton Mallet, they are deeply hidden by the oolitic strata.

Evercreech and West Pennard lie off this carboniferous limestone, but it extends beneath the valley in which these villages lie. Priddy is on the main anticlinal of the Priddy Mendip hills, and Chewton is separated from all the foregoing by the exposure of Old Red Sandstone. It would be interesting to know how far the Old Red Sandstone shared the movements ; but information is likely to be scanty, as the sandstone forms a bleak and sparsely inhabited region.

Mason College, Birmingham, January 6.

\section{Quaternionic Innovations.}

That Prof. Tait should not be able to do justice to those who prefer to treat vectors as vectors, and quaternions as quaternions, instead of commingling their diverse natures, with the result, in the latter case, of confusion of physical ideas (and geometrical also, for of course geometry is itself ultimately a physical science, having an experiential foundation), is naturally to be expected. He does not know their ways, either of thinking or of working, as is abundantly evident in all that he has written adversely to Prof. Willard Gibbs and others. It is, however, a little strange, in view of Prof. Tait's often expressed conservatism regarding Quaternionics, that he should tolerate any innovations therein, such as Mr. MacAulay has introduced. The latter may perhaps take this as a compliment to his analytical powers, which compel the former's admiration, and toleration of his departures from quaternionic usage. For myself, I welcome any quaternionic innovations that may (ultimately) tend in the direction of the standpoint assumed by Prof. Gibbs and others, and foresaw some two years since (when a very bulky manuscript came to me for my opinion) that there would be some quaternionic upstirring.

Prof. Gibbs has already pointed out how the development of Quaternionics has involved first the elimination of the imaginary, and next the gradual elimination of the quaternion! Now there is a capital illustration of this innate tendency in Prof. Tait's review (NATURE, December 28, 1893), where, on p. 194, he explains by an example the meaning of a startling innovation of Mr. MacAulay's. Put it, however, in vectorial form, and let us see what it comes to then. Take the case of a stress and the force to correspond (which is a little easier than Prof. Tait's example, though not essentially different). Let $\phi$ be a stress operator (pure, for simplicity), so that $\phi \mathbf{N}$, or $\mathbf{N} \phi$, is the stress per unit area on the $\mathbf{N}$ plane, $\mathbf{N}$ being any unit vector. Now we know, by consideration of the stresses acting upon the faces of a unit cube, that the $\mathbf{N}$ component of the force $\mathbf{F}$ per unit volume is the divergence of the stress vector for the $\mathbf{N}$ planes. That is,

$$
\mathbf{F} \mathbf{N}=\nabla \phi \mathbf{N},
$$

for any direction of $\mathbf{N}$. I employ my usual notation for the benefit of readers (now becoming numerous) who, though they cannot follow the obscure quaternionic processes, can understand the plainer ones of pure vector algebra. Now, may we remove the vector $\mathbf{N}$ (which is any one of an inlinite number of vectors) and write

$$
\mathbf{F}=\nabla \phi \text { or }=\phi \nabla
$$

simply, as the complete expression for the force? Certainly we may. For, in full, we have

$$
\begin{gathered}
\nabla=\mathbf{i} \nabla_{1}+\mathbf{j} \nabla_{2}+\mathbf{k} \nabla_{3}, \\
\phi=\phi_{1} \cdot \mathbf{i}+\phi_{2} \cdot \mathbf{j}+\phi_{3} \cdot \mathbf{k} \text { or }=\mathbf{i} . \phi_{1}+\mathbf{j} . \phi_{2}+\mathbf{k} . \phi_{3},
\end{gathered}
$$

where $\nabla_{1}$, \&c. are the scalar components of the vector $\nabla$ (not a quaternion, of course) and $\phi_{1}, \& c$. are the vector stresses on the planes of $\mathbf{i}$, \&c., so that $\phi_{1}=\phi \mathbf{i}$, \&c. Direct multiplication gives at once

$$
\nabla \phi=\nabla_{1} \phi_{3}+\nabla_{2} \phi_{2}+\nabla_{3} \phi_{3}
$$

which is $\boldsymbol{F}$. We may also write it $\phi \nabla$, because $\phi$ is pure.

$$
\text { No. I } 26_{3} \text {, voL. 49] }
$$

On the other hand, when $\phi$ is rotational, let its conjugate be $\phi^{\prime}$, then instead of (I) we have

and therefore

$$
\mathbf{F} \mathbf{N}=\nabla \phi^{\prime} \mathbf{N},
$$

$$
\mathbf{F}=\nabla \phi^{\prime}=\phi \nabla .
$$

Here if $\phi$ is given by the first expansion in (4), $\phi^{\prime}$ is given by the second.

Now there are several things that deserve to be pointed out about the above, which should be compared with Prof. Tait on p. 194. First, that the result $\mathbf{F}=\phi \nabla$, irrespective of pureness, or $\mathbf{F}=\nabla \phi$ also when the stress is pure, when got quaternionically seems to be a great novelty to Prof. Tait, and to give him a "severe wrench," involving a "dislocation" and a "startling innovation." Perhaps, however, it is only $\mathrm{Mr}$. Macaulay's peculiar way of arriving at the result, that Prof. Tait is alluding to. Moreover, secondly, in the vector algebra of Willard Gibbs and others the use of equation (2) or of $(7)$ to express the force complete, by removal of the intermediate vector $\mathbf{N}$, is neither new, nor does it involve any straining of the intellect, for it is actually a part of the system itself, done naturally and in harmony with Cartesian mathematics. See Gibbs's " Elements of Vector Analysis" (1881-4) for the direct product of $\nabla$ and $\phi$. (Also for the skew product, a more advanced idea ; it, too, is a physically useful result.) Thirdly, note how very differently the same thing presents itself to Prof. Tait according as it is clothed in his favourite quaternionic garb or in vectorial vestments. In the latter case it is either unnoticed or is contemptible; in the former, it may be a novel and valuable improvement.

I do not think that Prof. Tait does justice to Mr. MacAulay in making so much of a trifle such as passes unnoticed or unappreciated in the previous work of others. There is, I know, much more in Mr. MacAulay's mathematics than Prof. Tait has yet fathomed. For my own part, I like to translate it into vectors, not merely because it is then in a form I am used to, and is plainer, but also because the true inwardness of these processes involving linear operators is properly exhibited by the dyadical way of viewing them in conjunction with vectors, without the forced and unnatural amalgamation with quaternions, and the attendant obscurities. This seems to me to be particularly true in physical applications. I should not be writing this note were it not for the misconceptions that Prof. Tait indulges in about what he does not know, viz. vector algebra apart from quaternions. At the same time, to avoid possible misunderstanding, I disclaim any hostility to Mr. MacAulay's quaternionic innovations, although I must agree with Prof. Tait as to the "singular uncouthness" of some of his expressions in their present form. I hope he may be able to see his way to do his work vectorially. It will be more amenable to innovations, I think, without mental wrenches. At any rate he is a reformer, and not afraid to innovate when he thinks fit.

Paignton, Devon, December 30, 1893. Oliver Heaviside.

\section{The Second Law of Thermodynamics.}

I APOLOGISE to Mr. Bryan for unintentionally reading into the Report, Article I7, what he did not intend to be there. I understand now that according to his view conservative systems are not alone to be included in the Clausian proof.

My point, however, is (or was) that they ought to be excluded, at all events when there is only one controllable coordinate $v$, because ( $I$ ) in conservative systems the virial equation gives a relation between $\mathrm{T}$ and $v$, so that only one of them is independent. That, I submit, is true in fact. And (2) the second law, I said, requires two independent variables. That, however, is a question of definition, and if Mr. Bryan were to take the equation

$$
\int \frac{\partial Q}{T}=0
$$

for a complete cycle, whatever be the nature of the system, as a definition of the second law, I see no valid objection to that definition.

I admit, and did admit, that for a conservative system, moving in a complete cycle,

$$
\int \frac{\partial Q}{T}=0
$$

